\title{
A Systematic Literature Review Paper on Online Medical Mobile Applications in Malaysia
}

\author{
https://doi.org/10.3991/ijoe.v16i01.12263 \\ Nohman Khan \\ Universiti Kuala Lumpur, Kuala Lumpur, Malaysia \\ Muhammad Imran Qureshi ${ }^{(凶)}$ \\ Universiti Teknikal Malaysia Melaka, Malaysia \\ qureshi@utem.edu.my \\ Ishamuddin Mustapha \\ Universiti Kuala Lumpur, Kuala Lumpur, Malaysia \\ Sobia Irum \\ University of Behrain, Sakhir, Bahrain \\ Rai Naveed Arshad \\ University Teknologi Malaysia, Johor, Malaysia
}

\begin{abstract}
The introduction of mobile devices to the worldwide market has marvelous possible to disturb the way Health care is providing. In this paper, we will overview the work done in the five years from 2014 to 2018 in the field of mHealth in Research perspective. For that purpose, we choose the Scopus database to review the past research published on mHealth in Malaysia. For that purpose, the quantitative review has been observed in bibliometric analysis and a Qualitative review is done through systematic review in the order through PRISMA (Preferred Reporting Items for Systematic Review and MetaAnalysis). After the selection of 58 papers, the process based on the different steps. In the first step, the corresponding to Microsoft excels to a descriptive analysis of the published literature on mobile Healthcare in the field of online Healthcare like the distribution of the year, distribution of subjects and distribution of the author. Quantitative studies are 15 in number collected from the past literature, the researcher used the quantitative method for measuring the results Quantitative research collects data that will be processed to understand the indicators, overall trends, and requirements of the market. The qualitative studies collected from past research were 27 in numbers, collected studies were processed on the excel sheet to find out the areas discussed in the past. Traditional Health Care of Malaysia is top of the list in the world, but the mHealth still needs to improve in the region. Past studies in the mHealth are discussing physical health and wearable devices in details with connectivity to smartphones but serious diseases are cover in very some studies. Like diabetes and HIV apps and patient are not highlighted in the collected data. Patient record management and coordination with families are also part of some research studies and that is very important for recovery in some cases.
\end{abstract}

Keywords - Mobile applications, physical health, smartphones 


\section{Introduction}

The Malaysian health sector scored 95 percent out of 100 in the recent medical rankings, Malaysia takes the top spot in the Healthcare category of our Annual Global Retirement Index. The healthcare in the Southeast Asian gem is simply world-class with up-to-date and sophisticated infrastructure. With $13 \mathrm{JCI}$ accredited hospitals in the country and almost every doctor fluent in English. In fact, most doctors were trained in the UK, U.S., or Australia so communicating is flawless. Malaysia is one of the top tourist countries with medical assistance and facilities, The health facilities include in one of the top ranks in the report of Joint Commission International and two top score hospitals are available in Kualalumpur and two others are Penang, both cities are hustling and bustling with the tourists from all over the globe. Experts are normally choosing the hospital which is easily available and having quality services according to the requirements of patients and tourists in case of emergency, whether it may be private or public hospital. It is commonly believed that private hospitals are more expensive than public hospitals, but private hospitals standards are much similar to Western Healthcare Centers and hospitals. Some people are convinced on Private hospitals are very much relative fees with the Public hospitals and very economical for international Tourists due to more value of their currencies as compare to Malaysia. In Malaysia, you don't need to make a long appointment and wait for specialist doctors and any referral from the Government for emergency treatment. Its very simple to take a receipt from the receptionist and wait for your number for Doctor/specialist of choice. Malaysia healthcare sector is much cheaper as compared to many other countries of the world with high-level facilities, normally its very much equal to the same amount at home and fractionally more at the hospital for the local people. In Malaysia the pharmacist, medical staff and nurses are more trained and skillful with well-informed information about the latest changes in the medical field. Malay people are very simple and well-mannered people and genuinely take interest in that to impress, they are very friendly people and have a smile on their faces most of the time. ("The Best Healthcare and Healthcare Systems in the World 2019,") IL Malaysia Correspondent Keith Hockton, who lives in Penang says, "Recently, I decided on a whim to have a medical. I'd never had one done before and as I had a free morning, I decided just to pop into the Lam Wah Eee Hospital. I was already registered and found myself sitting outside a GP's office, not five minutes after arriving. Within an hour, I had been examined by a doctor, had an ECG and blood and urine tests done... and I was on my way home. "The total cost of the visit was just $\$ 44$. The doctor who had examined me called me later that afternoon with the results. It's this level of service that makes medical in Malaysia not only an attractive option but also a non-scary one. It's all so easy."

Most people from neighbor countries like Indonesia, Hong Kong, and Singapore have come to Malaysia for medical assistance due to low medical expenses and high rated health care services. Usually all doctors and specialist can speak English and most are professionally trained in the USA, UK, and Australia, that's why they are familiar with the Western standard of health care. Also, many of the hospitals in Kuala Lumpur and Penang are JCI accredited, meaning that they are considered to meet 
the gold standard in healthcare throughout the globe. More than 800,000 foreigners seek treatment in the hospitals in Penang and Kuala Lumpur every year. There are specialists in every hospital, but unlike in the U.S., you don't have to wait for months to get an appointment. Just turn up to the hospital, register, then take a number and wait your turn. If you are then referred to another doctor or need to get an X-ray or scan, that will also happen on the same day in the same place.

Prescriptions in Malaysia cost a third of what you pay at home. But it's not just the cost that's attractive; it's the service. The pharmacists, like the rest of Malaysia's medical staff, are well trained and informed. Malaysians are friendly people, but it's the genuine interest that they take in you, no matter how small or large the issue, which impresses. It takes you back to a time when personal service meant something. That same service is alive and well here. There are doctor's clinics throughout the country, which are perfect places to get treatment for something minor like a cold, flu, or sinus infection. They usually charge $\$ 10$ and because these are small clinics you won't have to wait if you would in a busy hospital. But for anything more serious, it's best to go to a specialist or general practitioner in one of the many top-notch hospitals in the country. A first-time doctor or specialist visit is usually between $\$ 15$ to $\$ 65$ with follow-up visits around $\$ 11$ to $\$ 28$. If you are admitted, the overnight stay will cost roughly $\$ 55$ to $\$ 200$ for a private room per night. Many of the hospitals offer health screening packages which include a physical, chest X-ray, ECG, blood work (43 different tests), abdomen ultrasound, and a vision test. More specific tests can be added on, but the basic package starts at less than $\$ 120$. Dentistry in Penang is just as high quality. Just like the doctors, most are schooled in the West and speak English. The technology is the same, and in some cases more advanced than at home, depending on the office you go to. Cleanings start at $\$ 22$ at a modern office with state-of-theart equipment, and it's only ("Healthcare in Costa Rica - International Living Countries,")\$29 for a filling. Porcelain crowns start at $\$ 400$, all just a fraction of the cost in the U.S.

There is a two-tier healthcare system in Malaysia; government-run universal healthcare and a co-existing private healthcare system. Expats can choose whatever hospital they want and pay out of pocket if they don't have insurance. Most expats choose to go to the private hospitals (which tend to be more expensive) instead of the public ones and will still save money when they pay out of pocket for most minor visits. Private health insurance is available, and many expats take out policies for any major health issues. International insurance companies like AIG, BUPA, and Cigna offer various plans for expats - some include medical coverage while you travel as well. ("Healthcare in Costa Rica - International Living Countries,")

The introduction of mobile devices to the worldwide market has marvelous possible to disturb the way Health care is providing. By 2021, The smartphone devices will expectedly to reach 1.5 Of these mobile devices, Smartphone and applications will most popular technology in the near future (Nussbaum et al., 2019). Since the internet creation and availability in every corner of the world, its great use, most importantly in the developing countries of the earth has generated another way of living life(Nussbaum et al., 2019). One of the more powerful instrument is Mobile Health; Internet developed a high reputation in telemedicine and telehealth, now present in 
every modern health care organization the mHealth corner is growing gradually (Martínez-Pérez, de la Torre-Díez, \& López-Coronado, 2013). Developing the field of mobile Health or Telehealth, eHealth has arrived as the new phenomena, technology, and commerce, with commerce and technology as tools in the service of health $(\mathrm{Oh}$, Rizo, Enkin, \& Jadad, 2005). In this paper, we will overview the work done in the last five years from 2014 to 2018 in the field of mHealth in Research perspective. For that purpose, we choose the Scopus database to review the past research published on mHealth in Malaysia.

\section{Methodology}

For the development of theory, a literature review is playing the role of facilitator, that is also helping to fulfill the possible research gaps, and highlight the areas where more or further research is needed within the available literature that are cover the topic (Y. Chen \& Zheng, 2019).

The main objective of the paper is to provide a systematic and realistic sketch of the mHealth in the last five years within Malaysia. For that purpose, the quantitative review has been observed in bibliometric analysis and a Qualitative review is done through systematic review in the order through PRISMA (Preferred Reporting Items for Systematic Review and Meta-Analysis) (Y. Chen \& Zheng, 2019).

There are four main steps for Literature review, Quality assessment, eligibility and inclusion criteria and the study included in qualitative and Quantitative relevant synthesis studies is employed (Figure 1). The descriptive literature reviews minimize the bias in a systematic review to identification, selection, synthesis and a brief summary of different studies.

The summarize the important results of the literature through the systematic review is not only done but also differentiations among the studies (Nussbaum et al., 2019). The study of a research topic evaluation, top trends and using frequent methodologies in bibliometrics use of Quantitative analysis to measure the importance of publications in the field-specific (J. Chen, Zhu, Liu, Chen, \& Yang, 2018). 


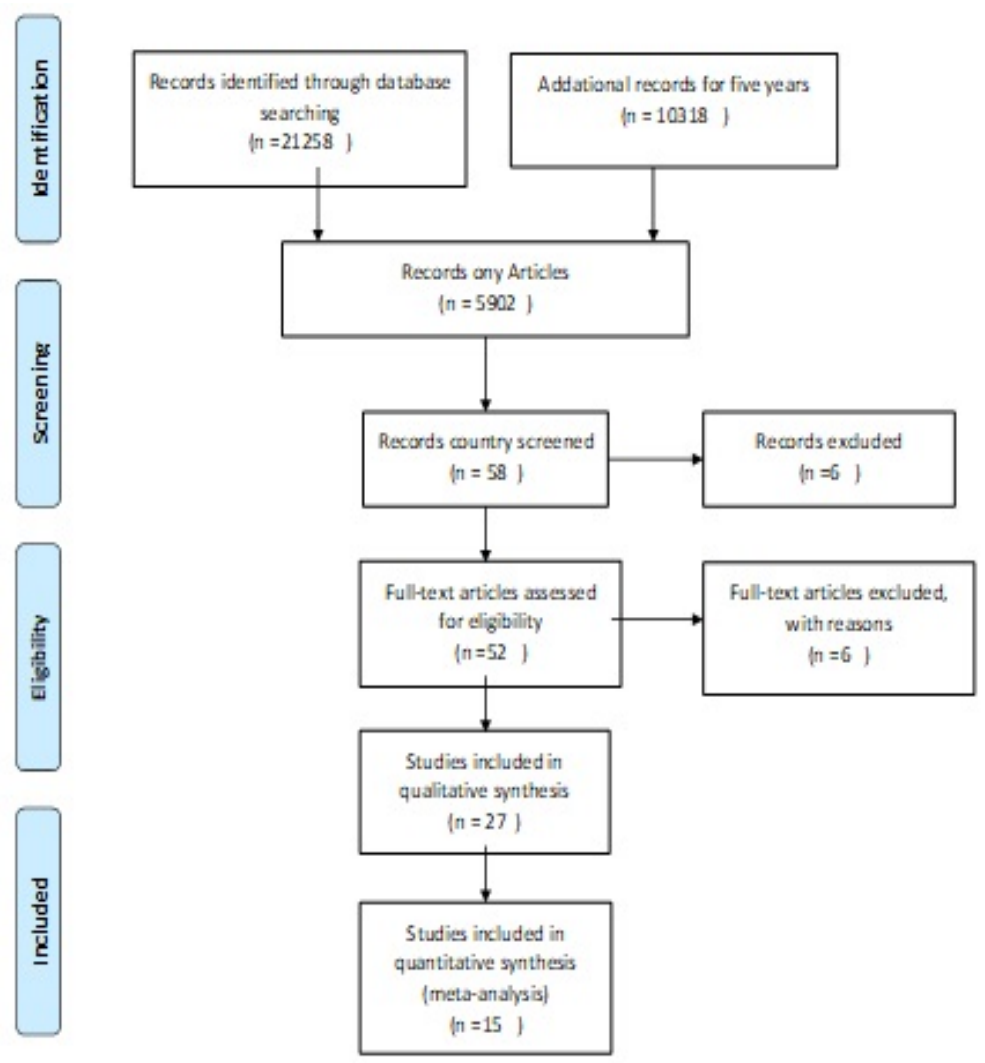

Fig. 1. PRISMA 2009 Flow Diagram

\section{$3 \quad$ Literature Research}

The possible comprehensive literature from the published research is collect from Database Scopus on the topic of mHealth in the years 2014 to 2018. The filtration of the language is used during the collection of data from the database, the papers are collected and selected only from Malaysia perspective of mHealth with filter option in the database. The all possible journals of the Scopus database are used for the collection of data, for the maximum collection of relevant data, the filter on the subject wise research is not utilized. The keywords are used for the data collection and search is "mobile AND healthcare", the total results were displayed by the database 21258 and when filter used for the years from 2014 to 2018, the result was found 10318. The document type for this review paper has only selected the Article and when the option used for the article only the surprising results were changed to 5902. The conference papers and review papers are not selected for the review. In the last when the country/region is selected for the review paper, only 58 studies were remains type for this review paper has only selected the Article and when the option used for the article 
only the surprising results were changed to 5902. The conference papers and review papers are not selected for the review. In the last when the country/region is selected for the review paper, only 58 studies were remains.

\subsection{Quality assessment}

The review paper is based on original articles, all the review papers, and conference papers were excluded during the process. The duplication of the papers was also checked very keenly to avoid the duplications of papers. Moreover, the abstract and conclusion were screened the narrow down the available records. Additionally, reference and citations were also checked.

\subsection{Eligibility and inclusion criteria}

The identified and available literature, papers were moved forward through a very comprehensive and highly accurate selection process. The articles in the languages are used and the English language is selected for the collected papers. The all possible journals in Scopus were selected for the data collection process. This paper reviews the mHealth literature and health-related applications are also included in the collection of data. Some of the studies also discussing the mobile wearable devices in the mHealth were also selected. During the selection articles with no open access and with open access are also selected. The number of qualitative studies is higher the quantitative in the study. The duplications of the papers are strictly monitored during the process.

\subsection{Studies included in qualitative synthesis}

After the selection of 58 papers, the process based on the different steps. In the first step, the corresponding to Microsoft excels to a descriptive analysis of the published literature on mobile Healthcare in the field of online Healthcare like the distribution of the year, distribution of subjects and distribution of the author. In the other step, the content analysis was done to identify and analyze the main research streams, reporting the absolute way on the different areas and also mentioning the future opportunities and challenges to research (Rodrigues \& Mendes, 2018).

\section{Results}

\subsection{Descriptive analysis}

The figure shows that there are many publications on the topic of mHealth many numbers of publications are published in the last five years. The mHealth is very much getting popularity as the digitalization of the economy growing day by day very rapidly. In this paper, the main concept is to find the overall work done on the mobile healthcare sector over the years. The Malaysian healthcare sector is the world best due 
to the resources and trained medical staff with highly scientific equipment at affordable prices ("The Best Healthcare and Healthcare Systems in the World 2019,"). The World Health Organization (WHO) Global Observatory for e-Health (GOe) defined $\mathrm{m}$-Health or mobile health as medical and public health practice supported by mobile devices, such as mobile phones, patient monitoring devices, personal digital assistants (PDAs), and other wireless devices (Ganasegeran, Renganathan, Rashid, \& Al-Dubai, 2017). The new era of mHealth is opening new dimensions of healthcare in Malaysia. The new trend indicates the more reliable and immediate way in case of emergency and form of applications, WhatsApp messages, and website availability of services make a batter way. The research shows that mobile applications are more helpful in old age people healthcare and distance people from Basic health units(Martínez-Pérez et al., 2013). This study shows that past studies in the field of mHealth direction and how the effective use of healthcare applications can people live a healthier life. Mobile Health applications are easily approachable to every single individual having the android phone. According to (Hussein, Oon, \& Fikry, 2017) The mobile technology features focus to manage health in the systematic and right direction. That also makes doctors allow the batter decisions about patient health. Generally, the mHealth is very impressive but the resist to usage is a challenge. In Malaysia, the intention to use the mHealth related applications are still questionable, this is a big issue for business and academic purpose (Hussein et al., 2017).

\subsection{Year base}

The graph of the publications shows the number of studies during the last five years from 2014 to 2018. The total number of publications collected from Scopus database are shown in the graph. The year 2018 is tip of the list with 22 research papers on Mobile Health. The results are showing that the Mobile health is gradually getting popular the years due to the importance in the medical field. The, more importantly, the year 2017, 16 and 15 are the same with having 10 publications each year. The results are showing that researchers are keenly observing the moble health with every passing year and the 2018 year is more batter and focused year for mobile healthcare. The year 2014 has only 6 studies on mobile health and that is a low number, comparatively after the 2014 years.

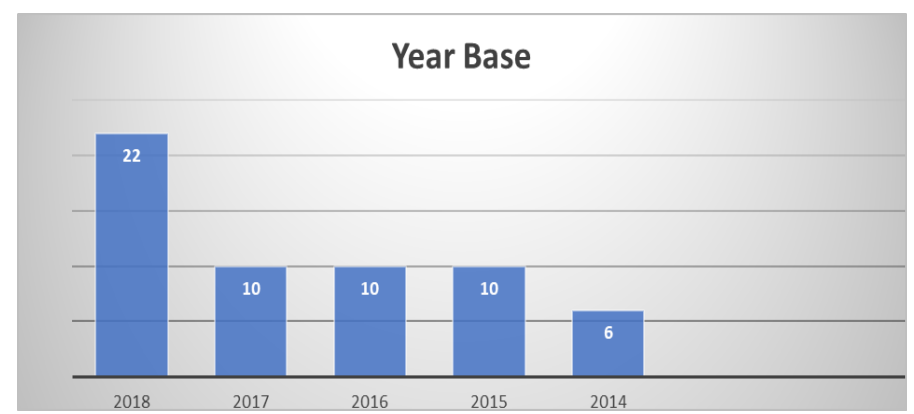




\subsection{Subject base}

The subject base chart is explained that the number of publications related to different subjects. The highest articles are related to medicine subject. The medicine subject is at the top numbers with $23 \%$ articles. The collected data is not limited to one subject that presents the diversity of the study. The medicine field researchers are working more efficiently on mHealth to open new opportunities for the patients. The second on the list of publications in the last five years is computer science subject. the subject is covering $21 \%$ publication are that is very high and important figure due to the involvement of computer and internet in the mHealth.

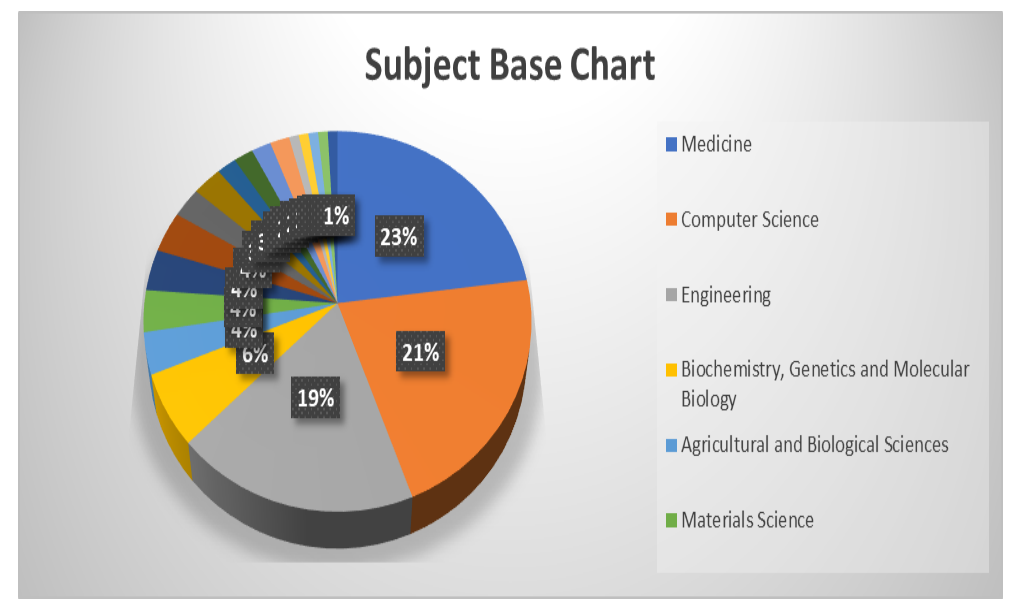

The Engineering base studies are $19 \%$ and the average is high as compare to the other subjects. The Biochemistry, Genetics and Molecular Biology are 5 large studies contained in the current study, with $6 \%$ publications. Agricultural and Biological Sciences, Materials Science, Pharmacology, Toxicology and Pharmaceutics and Social Sciences are having $4 \%$ articles from each subject. The other areas are also having articles in the study.

\subsection{Cited by}

The graph of the most cited articles in the study shows that the Advances in Smartphone-Based Point-of-Care Diagnostics is the article, which is cited 78 times and the author of the article is Husain, $\mathrm{W}$ with the other co-authors. The main author is affiliated with the School of Computer Sciences, Universiti Sains Malaysia, Penang, Malaysia. The citation of the article is very high as compared to the other articles collected in the review paper. Organizational decision to adopt hospital information system: An empirical investigation in the case of Malaysian public hospitals is the second-highest cited article with 42 times. The author Ahmadi, H., Faculty of Computing, Unversiti Teknologi Malaysia. The third most cited paper is Smart environment as a service: Three-factor cloud-based user authentication for telecare medical information system, that is cited 39 times and the other of the study is Siddiqui, Z. 


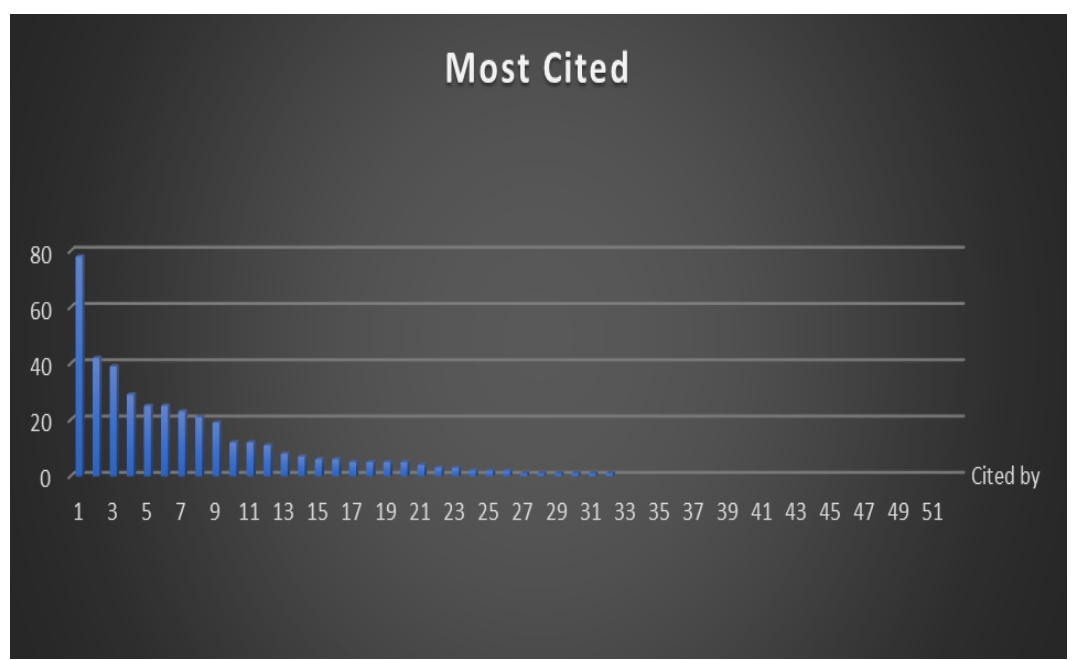

Gamification Solutions to Enhance Software User Engagement-A Systematic Review is the fourth most cited study collected for the review paper from the Scopus database. There are some other high studies shows in the graph. The number of high cited studies are collected from the Scopus and reviewed in the study.

\subsection{Journal base}

The journal base graph of the study shows that international Journal of Interactive Mobile Technologies articles were 5 and journal of Telecommunication, Electronic and Computer Engineering were also having 5 articles. Both journals published articles are collected from the Scopus database.

The mHealth is very much gaining the placements in the journals due to its importance in the research world. The International Journal of Human-Computer Interaction, Journal of Telecommunication, Electronic and Computer Engineering and PLoS ONE are the journals having the 4 papers each. The journals are very much placing research on the mHealth. 


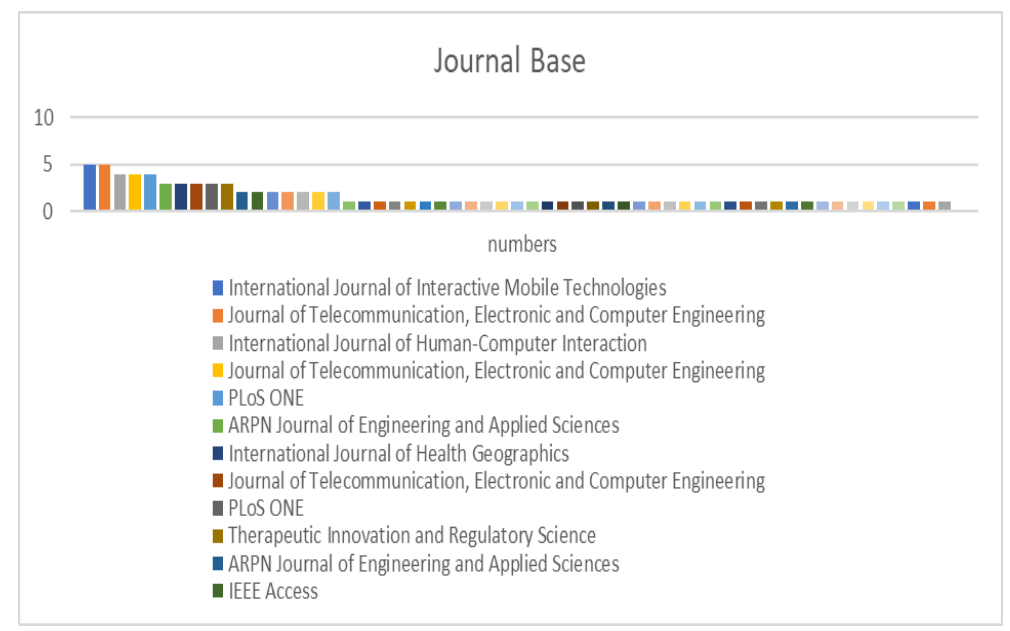

\section{Classification}

The published articles are processed in the Microsoft Excel sheet and open the process of classification for further review. The three main categories are decided to analyze and understand the work has been done. The past published literature is discussed in detail to find out the required information and future base agenda for the new researchers.

\subsection{Method base classification}

The detail and deep discussions are done in this section after the classified categories of the already work done.

\subsection{Quantitative method}

Quantitative studies are 15 in number collected from the past literature, the researcher used the quantitative method for measuring the results Quantitative research collects data that will be processed to understand the indicators, overall trends, and requirements of the market. An analytic create questions to find out the relationship between the factors involved in the survey (Song \& Zhang, 2019). The researcher has permission in quantitative research to find the theories are created deliberately to find some solutions to the problem. For that, there is the importance of performance and reason for performance, secondly available information is initially due to the statistic that is easily calculate able and summarizes (Song \& Zhang, 2019). The numeric data examination is done through mathematical standard procedures (Kim et al., 2002) and the last procedure is an arithmetic term used in quantitative research. Most of the collected Quantitative papers Health care of the patients and use statistical tools to find the results. Mobile Health can be accessed every android mobile user, now the 
mobile devices are very much easier to use with applications, to develop and improve the affordability, availability, and quality of the services provided by the devices in healthcare services (Marrie et al., 2019). Now the more powerful operating systems of the smartphones make users to install additional software and big data storage and fast processing capabilities. Due to the developed and more updated capabilities, smartphones are converted into handheld computers (Marrie et al., 2019). The clinical practice and research in the field accepted the great power of mHealth in the current time. By reshaping the communication and interaction between patient, doctors, and researchers to get more reliable data for quantitative research. The developments are significant and very relevance's to healthcare (Cvrkel, 2018). Some of the collected studies also discuss adult Mobile Health care, the adult is suspectable of mental incapacities and disabilities, Globally the using of mHealth in the older population is increasing quickly, as compared to any other age group, the reason behind that is life expectancy and a decrease in the birth rate (Alam, Hoque, $\mathrm{Hu}, \&$ Barua, 2020a). The mHealth is a revolution in health care, $m$ health can control the Heart Fails through self-management. Mobile phones are the ideal mediums to intervene in the Heart Fails. The mobiles phones are used as the large monitoring system and also smartphones can deliver the Heart Fail related educational messages for the patients (Cajita, Hodgson, Budhathoki, \& Han, 2017). This does not improve the quality of management but also control the mortality and quality of life. Some of the studies also discuss the very important matter of maternal health or pregnant women cares in past research. The pregnancy challenge of life not for a single but two lives are on stake. We need to set out and understand the needs and demands of a pregnant woman. In order to design a much better health management application to measure the realities and develop a food plan for maternal during the days of pregnancy (Peyton, Poole, Reddy, Kraschnewski, \& Chuang, 2014).

Some studies talked about mHealth applications for health care. The advancement of Mobile applications in mobile health is improving individual health, quality of life, shaping a healthy lifestyle and remote living patients monitored. The rule-based system is one of the most relevant components such as applications to overcome deductive mechanism reasoning ("Healthcare in Costa Rica - International Living Countries," 2018). Five billion smart users are using the phones worldwide and that is $85 \%$ used for commercial use. Approximately $63 \%$ of Malaysians are using the smartphones, almost every smartphone user is using the WhatsApp application that is one of the most compatible application. WhatsApp application is very popular Malaysia and world third leading smartphone internet using nation (Benedictis et al., 2019; Qureshi et al. 2019; Bhatti et al. 2018, Lim et al. 2018; Harasis et al. 2018, Shahverdi., Ismail \& Qureshi 2018, Rasli et al. 2015; Shafiq \& Qureshi 2014; Qureshi et al. 2014; Iftikhar \& Qureshi, 2014; Qureshi et al. 2013).

The Mobile Applications usage is significantly growing, the number of applications during the year 2010was 5820, that was on the health and wellness ("Research | mobi health news," 2011), during the year 2013, the number of applications was raised up to 17000 medical apps globally (Liu, Lin, \& Sadeh, 2014). The mobile applications are consistently gain the confidence and reliability from the patient prospectus. The number of users is still trusting very much to adopt the technology base 
application to enhance health care. By the year 2015, 500 million people are utilizing the services of the mobile apps and confidence is increasing day by day due to advancement in the android and IOS applications operating systems (Hageman, 2016). The mHeallth apps are more reliable and help in finding the instant solution in case of emergency. The researchers need to find mobile apps for the distance living community to find the access for medical assistance. The mobile apps are also helpful to save time of doctors and the patients. The applications are easily available in the play store and users can install.

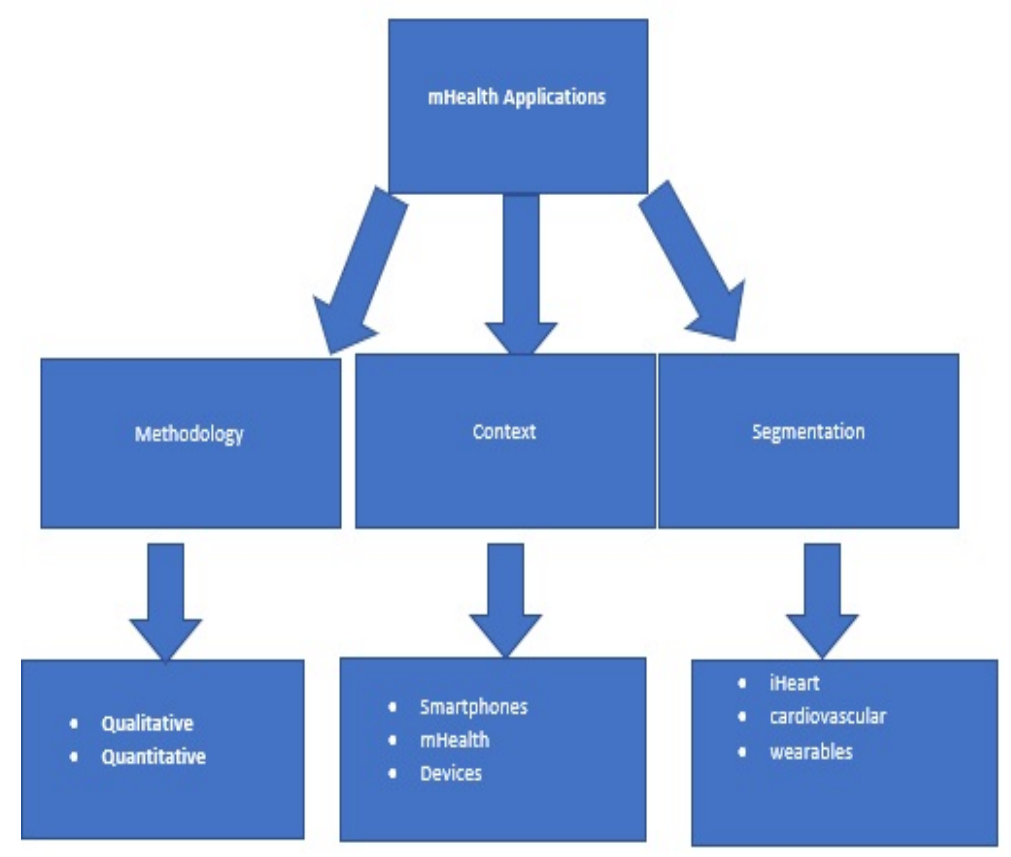

Fig. 2. Research Framework

\subsection{Qualitative method}

The qualitative sampling strategies for the qualitative reject by the many researchers due to not using the criteria of universal principle, but some researches appreciate the idea in qualitative research and called it a treasury idea for novel researchers (Curtis, Gesler, Smith, \& Washburn, 2000). In the current years, most of the qualitatively oriented health researchers are gaining popularity due to adding the values for the health care sector. The qualitative evidence in the process is stressed by the WHO (World Health Organization) for usefulness to assess the needs, the experience of the stakeholders and expectations of the patient, that is very much complex for the healthrelated decision making (Curtis et al., 2000). The qualitative studies collected from past research were 27 in numbers, collected studies were processed on the excel sheet to find out the areas discussed in the past. Patient management is very much disor- 
ganized and high error in clinical communications due to incompleteness. Traditional face to face meetings, appointment timings issues, and telephonic communications was very much hectic and adverse for the patients. The opportunity for the advancement and development in Clinical management was needed (McElroy, Ladner, Saf, \& 2013). The innovative and highly sophisticated advancement in the field of Clinical communications changes the perception and future of Patient management. The highspeed internet, smartphones connectivity with wifi and cheap internet packages for the android and iPhones make access to information easier and immediate responses on the situations (Ai et al., 2011). Clinical Communications are also revolutionized due to the technology advancements, now patient management system makes access to a large number of medical information, imaging reports are available instantly that saves time and give ultimate solution in minimum time (International Living, 2018). According to WHO, patient care with the help of the mobile devices and smartphones are the new horizon of mHealth for clinical communications, there are a number of tools like WhatsApp, WeChat, tango, Viber or line allowing health care professionals to create contact with the patients (Free et al., 2013). The applications are not only facilitating the message and call feature but also offering the video and audio messages. The practitioner can easily generate groups and allow multiple users to interact with each other (Beratarrechea et al., 2013). Mobile applications not only used for the social media level but some of the top business organizations apps also discussed in the literature, the apps are specifically designed for the purpose of medical assistance. The Zigbee (XBee) is also discussed in the study to control the high blood pressure, this is measuring the blood pressure without any usage of wire, the system is consist of the devices (Ling, Tan, Wong, \& Lee, 2015).

The developing countries are moving to adopt mHealth facilities very quickly due to less amount of infrastructure and high-volume population. mHealth not only achieve healthcare-related targeted but also integrated health system management such as sustainable health goals (Ling et al., 2015). The mHealth and health basic system is very much important for the government and policymakers to identify the future need and demand for health care of public like financial risks protection, quality essential of healthcare and affordable medicines for everyone (Istepanian, Jovanov, $\& \mathrm{~T}, 2008$ a). Self-observing devices are also nowadays coming up rapidly to monitor personal health schedules. The wearables are very smart and connected with smartphones to monitor and store the record. Wearable devices are maintaining records of fitness, calories burned and gain (Istepanian et al., 2008a). mHealth wearable devices are very much effective in disease removal to enhance the level of fitness. Development of mHealth devices open the options of personal doctor to maintain selfcare (Alam, Hoque, Hu, \& Barua, 2020). Wearable devices or tools of mHealth are provided the real-time data and health measurements that is user engagement. The engagement is defined as the way people are using resources and smartphone applications (Istepanian et al., 2008a). Collected research discusses wearable devices to a real-time game-changer in individual health care. Qualitative studies are more talking about the mHealth applications for wearables and smartphone applications use for individual fitness and basic healthcare issues. There is still the development of mHealth applications are not at an appropriate level. The researchers are lacking to 
discuss maternal health, old age citizens health care and serious illness. The researcher needs to extend research find out batter way to create the growth.

\subsection{Segmentation and context}

The most important section of the study is to the discussion made upon segment and context discuss in past literature from Scopus database drive papers. Most of the literature is not able to explain or define mHealth in a convincing manner. The term mHealth is driven near in twenty century from the landscape of health technologies and the discipline to which they were used. The comprehensive definition or domain are not explained but the elements and tools are suggested. In this study, we will look upon the ontology of mHealth and construct of the term from the collected data (Istepanian, Jovanov, \& T, 2008). The (Istepanian et al., 2008) defines the mHeallth “ smartphone or mobile computing, medical sensor and communication technologies for healthcare". The article suggested that "endless mobility and wireless global healthcare connectivity". The recent most articles are defining as the process is moving towards the targeted personalized system with adaptable elements with compatibility with future updated $4 \mathrm{G}$ and $5 \mathrm{G}$ networks. This definition is very much concentrating on the hardware and network transitions with the passage of time connectivity with medical transitions. The World Health Organization (WHO) is still missing the standardized definition of mobile health or mHealth (WHO, 2011). The mobile devices, patient monitoring devices, personal digital assistants are promoting or supporting medical practices or applications, radio messages, mobile messages, and mobile phone support $3 \mathrm{G}$ and $4 \mathrm{G}$ networks. The WHO also including the Global Positioning System (GPS) and Bluetooth technology(WHO, 2011) (Speciale \& Freytsis, 2013).

Mobile health segment is frequently discussed in the context and focus section of the collected data from past articles. The usage of information technology (IT) was developing after the twenty century raised many questions about the health care of individuals and masses. The innovation needs to enhance the healthcare facilities effective tools of health was a great debate. The mHealth concept was to approach the rural areas for health care awareness and possibilities (WHO, 2016). A study discusses the integration of Malay Traditional Medicines with modern medicines in postnatal care. Traditional Malay medicines and western medicines are usually based in a different system and in isolation, but the concept of the researcher was to integrate services through an application MyPostnatalSys. The study concludes that healthcare will get the benefit from the standardization of exchanging the tools and information with an individual's health cares(Istepanian et al., 2008). Another area is discussed in the collected data is about Atrial Fibrillation which is an unfamiliar medical condition for the general patients, AF is very dangerous for the low literacy patients about the medical situation (Ayyaswami, Padmanabhan, Crihalmeanu, et al., 2019). Cardiovascular diseases also reported by some of the groups during the collected data (Ayyaswami, Padmanabhan, Patel, et al., 2019). The applications are needed to improve the quality and educate the patient about self-care for AF. Studies determine the accuracy and effectiveness of mobile apps in google play store and also in the apple app, the mobile health apps are growing more and more in users. The content and accessi- 
bility to users are measures in the studies and it is found that most apps are lacking scientific validation and need reading-grade beyond the high education (J. Chen et al., 2018).

Weight management is also discussed by some studies, smartphones and wearable devices are very much effective in weight control and physical health care. (Dounavi \& Tsoumani, 2019) believes that chronic disease is very effectively controlled through weight management. In the last few years, researchers are reviewing the literature about weight management and generating awareness about healthy foods and achieving physical health with the use of applications to control weight. Some studies in Malaysia talks about mental health too, mental health is a very hot topic in recent years due to anxiety and depression. Clinicians moved some portable applications and devices as a tool to aid and support in the rehabilitation of patients (Torous, Staples, Reports, \& 2015). The patients are feeling not good and confidence to attend face to face therapy, results are very much effective to reduce the mental illness. Professional believes that when mobile applications used with medication to decrease the mental illness much more result-oriented (Alamri, 2015). In the literature, a study discusses the Coronary Heart Diseases, in middle-income countries and middle east countries heart disease is very dangerous and most killer cause of the death (Motlagh, O'Donnell, \& Yusuf, 2009). In addition, Cardiovascular disease is one of the most killer cause in Malaysia also due to its dangerous history in patients. The researcher introduces the idea of IHeart mobile application that is a location-based cardiac emergency system to observe and monitor the victims of hypertension and arrhythmia. iHeart is designed to monitor patients, it must create a relationship between patient, Health care professionals and affected families for needs and feedback (Motlagh et al., 2009).

The segment of the study overview most of the apps that are designed and identify in collected past data from the Scopus database. Mobile applications are very much effective for the patient health care in Malaysia, development of networks into $4 \mathrm{G}$ and $5 \mathrm{G}$ create more options for users to adapt the technology base apps. Some of the researches talk about the mHealth is needed to create value for patients. Mobile applications are in good quality, but some time google play store showing applications with low quality and demanding too much personal information, that causes security concerns for the users. The applications are needed to improve more and reliability of the users.

\section{Conclusion}

After processing 58 research papers from the Scopus database, cannot avoid the evidence and the majority of Articles are dominant in mHealth through long term management. However, mHealth apps are still needed to improve in many dimensions. No dout about it mHealth is a hot topic in the current scenario, WTO believes that mHealth apps have the ability to change traditional health care trends into mHealth centers. In Malaysia, mHealth apps are very common and the availability of internet with android smartphones are growing day by day. Traditional Health Care of Malay- 
sia is top of the list in the world, but the mHealth still needs to improve in the region. Past studies in the mHealth are discussing physical health and wearable devices in details with connectivity to smartphones but serious diseases are cover in very some studies. Like diabetes and HIV apps and patient are not highlighted in the collected data. Patient record management and coordination with families are also part of some research studies and that is very important for recovery in some cases. The security concerns are related to mHealth apps and some people are not trusting apps due to too much information asked by applications during installation. Researchers need to point out the agenda in future studies to overcome the concerns of users about security issues. Normally mHealth applications are very much user-friendly and people with a basic education can use very comfortably the features of apps. Some applications are still very much complicated, especially with old people and uneducated users of smartphones. The collected studies are explaining that apps need to be more and more user-friendly because its help to deliver batter mHealth among the citizens of Malaysia.

\section{$7 \quad$ References}

[1] Ai, J., Chhanabhai, P., Wu, R., Rossos, P., Quan, S., Reeves, S., Morra, D. (2011). An Evaluation of the Use of Smartphones to Communicate Between Clinicians: A MixedMethods Study. Journal of Medical Internet Research, 13(3). https://doi.org/10.2196/ imir. 1655

[2] Alam, M. Z., Hoque, M. R., Hu, W., \& Barua, Z. (2020a). Factors influencing the adoption of mHealth services in a developing country: A patient-centric study. International Journal of Information Management, 50, 128-143. https://doi.org/10.1016/j.ijinfomgt.2019.04.016

[3] Alam, M. Z., Hoque, M. R., Hu, W., \& Barua, Z. (2020b). Factors influencing the adoption of mHealth services in a developing country: A patient-centric study. International Journal of Information Management, 50, 128-143. https://doi.org/10.1016/j.ijinfomgt.2019.04.016

[4] Alamri, Y. (2015, May 19). Mental illness in Saudi Arabia: Stigma and acceptability. International Journal of Social Psychiatry. https://doi.org/10.1177/0020764016628896

[5] Ayyaswami, V., Padmanabhan, D. L., Crihalmeanu, T., Thelmo, F., Prabhu, A. V., \& Magnani, J. W. (2019). Mobile health applications for atrial fibrillation: A readability and quality assessment. International Journal of Cardiology. https://doi.org/10.1016/j.ijcard.20 $\underline{19.07 .026}$

[6] Ayyaswami, V., Padmanabhan, D., Patel, M., Prabhu, A. V., Hansberry, D. R., Agarwal, N., \& Magnani, J. W. (2019). A Readability Analysis of Online Cardiovascular DiseaseRelated Health Education Materials. HLRP: Health Literacy Research and Practice, 3(2), e75-e80. https://doi.org/10.3928/24748307-20190306-03

[7] Benedictis, A. De, Lettieri, E., Masella, C., Gastaldi, L., Macchini, G., Santu, C., \& Tartaglini, D. (2019). WhatsApp in hospital? An empirical investigation of individual and organizational determinants to use. PLoS ONE, 14(1), e0209873. https://doi.org/10.1371/ journal.pone. 0209873

[8] Beratarrechea, A., Lee, A. G., Willner, J. M., Jahangir, E., Ciapponi, A., \& Rubinstein, A. (2013). The Impact of Mobile Health Interventions on Chronic Disease Outcomes in Developing Countries: A Systematic Review. Telemedicine and E-Health, 20(1), 75-82. https ://doi.org/10.1089/tmj.2012.0328 
[9] Bhatti, M. N., Sami, A., \& Qureshi, I. (2018). Personality and academic performance among graduate students. Asia Proceedings of Social Sciences, 2(3), 256-259. https://doi. org/10.31580/apss.v2i3.454

[10] Cajita, M. I., Hodgson, N. A., Budhathoki, C., \& Han, H. R. (2017). Intention to Use mHealth in Older Adults with Heart Failure. Journal of Cardiovascular Nursing, 32(6), E1-E7. https://doi.org/10.1097/jen.0000000000000401

[11] Chen, J., Zhu, X., Liu, G., Chen, W., \& Yang, D. (2018, May 1). China's rare earth dominance: The myths and the truths from an industrial ecology perspective. Resources, Conservation and Recycling. Elsevier. https://doi.org/10.1016/j.resconrec.2018.01.011

[12] Chen, Y., \& Zheng, B. (2019, March 1). What happens after the rare earth crisis: A systematic literature review. Sustainability (Switzerland). https://doi.org/10.3390/su11051288

[13] Curtis, S., Gesler, W., Smith, G., \& Washburn, S. (2000). Approaches to Sampling and Case Selection. Social Science and Medicine, 50(7-8), 1001-1014. Retrieved from https://www.sciencedirect.com/science/article/pii/S0277953699003500. https://doi.org/10. 1016/s0277-9536(99)00350-0

[14] Cvrkel, T. (2018). The ethics of mHealth: Moving forward. Journal of Dentistry, 74, S15S20. https://doi.org/10.1016/j.jdent.2018.04.024

[15] Dounavi, K., \& Tsoumani, O. (2019, June). Mobile Health Applications in Weight Management: A Systematic Literature Review. American Journal of Preventive Medicine. https ://doi.org/10.1016/j.amepre.2018.12.005

[16] Free, C., Phillips, G., Galli, L., Watson, L., Felix, L., Edwards, P., Haines, A. (2013). The Effectiveness of Mobile-Health Technology-Based Health Behaviour Change or Disease Management Interventions for Health Care Consumers: A Systematic Review. PLoS Medicine, 10(1), e1001362. https://doi.org/10.1371/journal.pmed.1001362

[17] Ganasegeran, K., Renganathan, P., Rashid, A., \& Al-Dubai, S. A. R. (2017). The m-Health revolution: Exploring perceived benefits of WhatsApp use in clinical practice. International Journal of Medical Informatics, 97, 145-151. https://doi.org/10.1016/j.ijmedinf.2016. $\underline{10.013}$

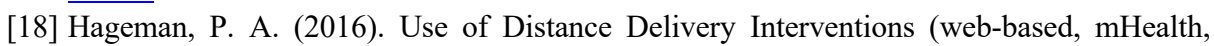
telehealth) for Hard-to-reach, Vulnerable Midlife and Older Individuals Use of Distance Delivery Interventions (Web-based, mHealth, Telehealth) for Hard-to-Reach, Vulnerable Midlife and Older Ind. In Posters and Presentations: Physical Therapy (p. 20). Retrieved from https://digitalcommons.unmc.edu/cahp_pt_pres/1/

[19] Harasis, A. A., Qureshi, M. I., \& Rasli, A. (2018). Development of research continuous usage intention of e-commerce. A systematic review of literature from 2009 to 2015. International Journal of Engineering \& Technology, 7(2.29), 73-78. https://doi.org/10.14419/ ijet.v7i2.29.13133

[20] Healthcare in Costa Rica - International Living Countries. (n.d.). Retrieved July 10, 2019, from https://internationalliving.com/countries/malaysia/healthcare-in-malaysia/

[21] Hussein, Z., Oon, S. W., \& Fikry, A. (2017). Consumer Attitude: Does It Influencing the Intention to Use mHealth? In Procedia Computer Science (Vol. 105, pp. 340-344). Elsevier. https://doi.org/10.1016/j.procs.2017.01.231

[22] Iftikhar, M., \& Qureshi, M. (2014). Modeling the Workplace Bullying the Mediator ofWorkplace Climate-Employee Health Relationship. Journal of Management Info, 4(1), 96124. https://doi.org/10.31580/jmi.v4i1.27

[23] International Living. (2018). The Best Healthcare and Healthcare Systems in the World 2018. Retrieved July 10, 2019, from https://internationalliving.com/countries-besthealthcare-world 
[24] Istepanian, R., Jovanov, E., \& T, Z. Y. (2008a). Guest Editorial Introduction to the Special Section on M-Health: Beyond Seamless Mobility and Global Wireless Health-Care Connectivity. IEEE Transactions on Information Technology in Biomedicine, 8(4), 556-566. https://doi.org/10.1109/titb.2004.840019

[25] Istepanian, R., Jovanov, E., \& T, Z. Y. (2008b). Guest Editorial Introduction to the Special Section on M-Health: Beyond Seamless Mobility and Global Wireless Health-Care Connectivity. IEEE Transactions on Information Technology in Biomedicine, 8(4). https:// doi.org/10.1109/titb.2004.840019

[26] J., T., P., S., \& J.-P., O. (2015). Realizing the Potential of Mobile Mental Health: New Methods for New Data in Psychiatry. Current Psychiatry Reports, 17(8). https://doi.org/10. 1007/s11920-015-0602-0

[27] Kim, K.-R., Kim, G., Kim, K., Lobanov, V., Ponomarev, V., \& Salyuk, A. (2002). A sudden bottom-water formation during the severe winter 2000-2001: The case of the East/Japan Sea. Geophysical Research Letters, 29(8), 75-1-75-4. https://doi.org/10.1029/ 2001gl014498

[28] Lim, J., Lim, K., Heinrichs, J., Al-Aali, K., Aamir, A., \& Qureshi, M. (2018). The role of hospital service quality in developing the satisfaction of the patients and hospital performance. Management Science Letters, 8(12), 1353-1362.Ling, T. H. Y., Tan, J. E. H., Wong, L. J., \& Lee, C. K. (2015). Blood pressure monitoring device with zigBee (XBee) wireless protocol and microsoft visual studio computer interfacing. International Journal of Simulation: Systems, Science and Technology, 16(4), 9.1-9.8. https://doi.org/10.5013/IJ SSST.a.16.04.09, https://doi.org/10.5267/j.msl.2018.9.004

[29] Liu, B., Lin, J., \& Sadeh, N. (2014). Reconciling mobile app privacy and usability on smartphones. In Proceedings of the 23rd international conference on World wide web WWW '14 (pp. 201-212). https://doi.org/10.1145/2566486.2568035

[30] Marrie, R. A., Leung, S., Tyry, T., Cutter, G. R., Fox, R., \& Salter, A. (2019). Use of eHealth and mHealth technology by persons with multiple sclerosis. Multiple Sclerosis and Related Disorders, 27, 13-19. https://doi.org/10.1016/j.msard.2018.09.036

[31] Martínez-Pérez, B., de la Torre-Díez, I., \& López-Coronado, M. (2013). Mobile health applications for the most prevalent conditions by the World Health Organization: review and analysis. Journal of Medical Internet Research, 15(6), e120. https://doi.org/10.2196/jmir. $\underline{2600}$

[32] McElroy, L., Ladner, D., Saf, J. H.-B. Q., \& 2013, U. (n.d.). The role of technology in clinician-to-clinician communication. Qualitysafety.Bmj.Com. Retrieved from https://quality safety.bmj.com/content/22/12/981?papetoc $=$ https://doi.org/10.1136/bmjqs-2013-002191

[33] Motlagh, B., O’Donnell, M., \& Yusuf, S. (2009, June). Prevalence of cardiovascular risk factors in the middle east: A systematic review. European Journal of Cardiovascular Prevention and Rehabilitation. https://doi.org/10.1097/hjr.0b013e328322calb

[34] Nussbaum, R., Kelly, C., Quinby, E., Mac, A., Parmanto, B., \& Dicianno, B. E. (2019). Systematic Review of Mobile Health Applications in Rehabilitation. Archives of Physical Medicine and Rehabilitation. https://doi.org/10.1016/j.apmr.2018.07.439

[35] Oh, H., Rizo, C., Enkin, M., \& Jadad, A. (2005, February 24). What is eHealth (3): A systematic review of published definitions. Journal of Medical Internet Research. Journal of Medical Internet Research. https://doi.org/10.2196/jmir.7.1.e1

[36] Peyton, T., Poole, E., Reddy, M., Kraschnewski, J., \& Chuang, C. (2014). "Every pregnancy is different": Designing mHealth interventions for the pregnancy ecology. In Proceedings of the Conference on Designing Interactive Systems: Processes, Practices, Methods, and Techniques, DIS (pp. 577-586). https://doi.org/10.1145/2598510.2598572 
[37] Qureshi, M. I., Rasiah, R. A., Al-Ghazali, B. M., Haider, M., \& Jambari, H. (2019). Modeling Work Practices under Socio-Technical Systems for Sustainable Manufacturing Performance. Sustainability, 11(16), 4294. https://doi.org/10.3390/su11164294

[38] Qureshi, M. I., Janjua, S. Y., Zaman, K., Lodhi, M. S., \& Tariq, Y. B. (2014). Internationalization of higher education institutions: implementation of DMAIC cycle. Scientometrics, 98(3), 2295-2310. https://doi.org/10.1007/s11192-013-1163-9

[39] Qureshi, M. I., Iftikhar, M., Bhatti, M. N., Shams, T., \& Zaman, K. (2013). Critical elements in implementations of just-in-time management: empirical study of cement industry in Pakistan. SpringerPlus, 2(1), 645. https://doi.org/10.1186/2193-1801-2-645

[40] Research | mobihealthnews. (n.d.). Retrieved July 20, 2019, from https://www.mobihealth news.com/research/the-world-of-health-and-medicalapps/

[41] Rodrigues, M., \& Mendes, L. (2018, April). Mapping of the literature on social responsibility in the mining industry: A systematic literature review. Journal of Cleaner Production. https://doi.org/10.1016/i.jclepro.2018.01.163

[42] Rasli, A. M., Norhalim, N., Kowang, T. O., \& Qureshi, M. I. (2015). Applying managerial competencies to overcome business constraints and create values: Evidence from small technology-based firms in Malaysia. Journal of Management Info, 2(2), 22-28.Song, Y., \& Zhang, Q. (2019). Quantitative research on gas explosion inhibition by water mist. Journal of Hazardous Materials, 363, 16-25. https://doi.org/10.31580/jmi.v3i1.15

[43] Shahverdi, M., Ismail, K., \& Qureshi, M. (2018). The effect of perceived barriers on social entrepreneurship intention in Malaysian universities: The moderating role of education. Management Science Letters, 8(5), 341-352. https://doi.org/10.5267/j.msl.2018.4.014

[44] Shafiq, M., \& Qureshi, M. I. (2014). Quadruple culture type approaches impacting employees attributes. Journal of Management Info, 1(2), 1-11. https://doi.org/10.31580/jmi.v2 $\underline{\mathrm{i} 1.3}$

[45] Speciale, A. M., \& Freytsis, M. (2013). MHealth for Midwives: A Call to Action. Journal of Midwifery and Women's Health, 58(1), 76-82. https://doi.org/10.1111/j.1542-2011.20 12.00243.x

[46] WHO. (2011). mHealth: New horizons for health through mobile technologies. Observatory, 3(June), 112. https://doi.org/ISBN 9789241564250

[47] WHO. (2016). Based on the findings of the third global survey on eHealth 2015 Global Observatory for eHealth Atlas of eHealth country profiles. Retrieved from https://scholar.google.com/scholar_lookup?title=Atlas of eHealth Country Profiles\%3A the use of eHealth in Support of Universal Health Coverage\%3A Based on the Findings of the Third Global Survey on eHealth\&publication year=2015\&author=WHO. https://doi. org/10.5772/47922

\section{Authors}

Nohman Khan works in UNIKL Business School in Universiti Kuala Lumpur at Malaysia. E-Mail: nohman.khan@s.unikl.edu.my

Muhammad Imran Qureshi works at the Faculty of Technology Management and Technopreneurship in Universiti Teknikal Malaysia Melaka. E-mail: qureshi@,utem.edu.my

Ishamuddin Mustapha works for Malaysian Institute of Industrial Technology at Universiti Kuala Lumpur in Malaysia. E-Mail: ishamuddin@unikl.edu.my 
Sobia Irum works as an Assistant Professor in College of Business Administration affiliated to University of Behrain. E-mail: sobiasafdar@yahoo.com

Rai Naveed Arshad works at VAT in University Teknologi Malaysia at Skudai state in Johor City of Malaysia.

Article submitted 2019-11-08. Resubmitted 2019-12-07. Final acceptance 2019-12-10. Final version published as submitted by the authors. 